\title{
Molecular docking based virtual screening of the breast cancer target NUDT5
}

\author{
Razia Sultana ${ }^{1, a *}$, Monjia Islam ${ }^{1, a}$, Md. Azizul Haque ${ }^{2}$, Fatematuz Zuhura Evamoni ${ }^{1}$, Zahid \\ Mohammad Imran', Jabunnesa Khanom ${ }^{1}$, Md. Adnan Munim ${ }^{1}$
}

1Department of Biotechnology and Genetic Engineering, Faculty of Science, Noakhali Science and Technology University, Noakhali-3814; 2Department of Applied Chemistry and Chemical Engineering, Faculty of Engineering and Technology, Noakhali Science and Technology University, Noakhali-3814, Razia Sultana E-mail: razia@nstu.edu.bd; *Corresponding author; aEqual contribution.

Received November 5, 2019; Revised November 28, 2019; Accepted November 29, 2019; Published December 5, 2019

Abstract:

DOI: $10.6026 / 97320630015784$

Breast cancer affects one in eight women in Bangladesh and is the most common cancer among women in South Asia next to skin cancer. NUDT5 are nucleotide-metabolizing enzymes (NUDIX hydrolases) linked with the ADP ribose and 8-oxo-guanine metabolism. It is known to be associated with the hormone dependent gene regulation and proliferation in breast cancer cells. It blocks progestin-dependent, PARderived nuclear ATP synthesis and subsequent chromatin remodeling, gene regulation and proliferation in this context. We describe the structure based binding features of a lead compound (7-[[5-(3, 4-dichlorophenyl)-1,3,4-oxadiazol-2-yl]methyl]-1,3-dimethyl-8piperazin-1ylpurine-2,6-dione- $\mathrm{C}_{20} \mathrm{H}_{20} \mathrm{C}_{12} \mathrm{~N}_{8} \mathrm{O}_{3}$ ) with NUDT5 for further in vitro and in vivo validation. It is a promising inhibitor for blocking NUDT5 activity. Thus, structure based virtual screening is used to identify a potential therapeutic inhibitor for NUDT5.

Keywords: Breast cancer, NUDT5 protein, Homology modelling, Molecular docking.

\section{Background:}

Breast cancer is the most lethal disease in women and is the second leading cause of cancer-related deaths in the United States [1] with symptoms such as a lump in the breast, a change in breast shape, dimpling of the skin and fluid coming from the nipple, a newly-inverted nipple, or a red or scaly patch of skin [4] depending on cancer type/stage and patient's age [2]. Survival rates in the developed world are high [3], with between 80 and $90 \%$ in England and the United States alive for at least 5 years [5, 6]. Worldwide, breast cancer is the leading type of cancer in women, accounting for $25 \%$ of all cases, in 2018 with 2 million new cases and 627,000 deaths [6]. The enzyme NUDT5 (nucleotide diphosphate hydrolase type 5) catalyzes the ADP (Adenosine diphosphate) ribose derived from hydrolysis of poly (ADP-Ribose) and pyrophosphate (PPi) are converted to ATP. It is known that NUDT5 is an upstream regulator of tumor drivers and are a biomarker for cancer stratification, as well as a target for drug discovery towards the treatment of aggressive cancer types and metastasis [7]. It is also known that NUDT5 protein plays noteworthy roles in regulating the G1-S transition in mammalian [9]. It is also known that NUDT5 (also referred as NUDIX5) has been linked to hormone dependent gene regulation and proliferation in breast cancer cells. The NUDIX hydrolases are a core family of nucleotide metabolizing enzymes that have critical roles in health and disease [11]. Thus, NUDT5 is an attractive target for drug design against breast cancer.

The use of structure-based virtual screening for finding effective compounds for designing a drug against breast cancer is getting momentum in the last decade [10]. We used the structure NUDT5 (PDB ID: 5NWH) from protein data bank [12] for this study. We used protein-ligand complexes (PDB ID: 5NWH, 3BM4, 2DSD, 


\section{BIOINFORMATION \\ Discovery at the interface of physical and biological sciences}

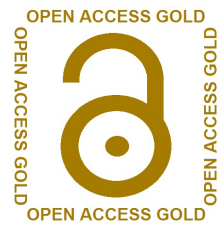

3L85) of NUDT5 from protein data bank (PDB). Two predominant substrates have been identified for NUDT5: 8 oxo-dGDP and adenosine 5 ' diphosphate [15-19] and these are important signally molecules [20-23]. It is further known that NUDT5 hydrolyzes 8oxo-dGDP under basic conditions $(\mathrm{pH} \approx 10)$ [15] as shown in Figure 1. Moreover, NUDT5 links with several critical events of cell progressing in relation to breast cells is known [23-24]. Therefore, it is of interest to use high throughput screening strategy to identify the small molecule inhibitor to NUDT5 using structure based drug design and molecular docking.

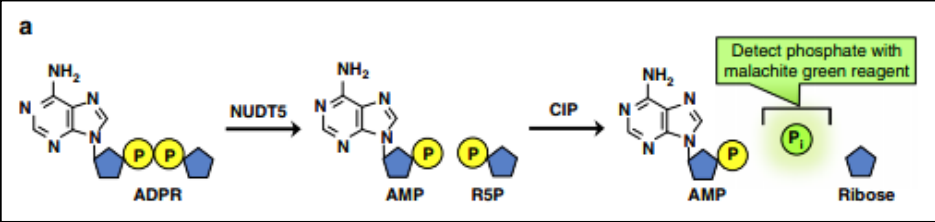

Figure 1: A representation of the enzyme-coupled malachite green assay (MG assay). ADPR is hydrolyzed to AMP and R5P by NUDT5, and then R5P is converted to free inorganic phosphate detected by the malachite green reagent.

Materials and methods:

NUDT5 protein model as target:

A reasonable protein model [27] of NUDT5 was developed using the tools Easy MODELLERTM and SWISS-PROT.

\section{Active side prediction in NUDT5:}

The residue around active site of the protein was predicted by using CASTp [28]. The X-ray diffraction structure of the breast cancer regulator NUDT5 (PDB Code: 5NWH) in complex with twenty carbon compound 7-[[5-(3, 4-dichlorophenyl)-1,3,4oxadiazol-2-yl]methyl]-1,3-dimethyl-8-piperazin-1-yl-purine-2,6dione- $\mathrm{C}_{20} \mathrm{H}_{20} \mathrm{Cl}_{2} \mathrm{~N}_{8} \mathrm{O}_{3}$ resolved at $2.6 \AA$ resolution were used as the basis of the docking experiments.

\section{Ligand compounds:}

Four different ligands sourced from PDB (PDB ID: 5NWH, 3BM4, 2DSD, 3L85) used in this study (Table 1) are given below:

[1] 7-[[5-(3,4-dichlorophenyl)-1,3,4-oxadiazol-2-yl]methyl]-1,3dimethyl-8-piperazin-1-yl-purine-2,6-dione- $\mathrm{C}_{20} \mathrm{H}_{20} \mathrm{Cl}_{2} \mathrm{~N}_{8} \mathrm{O}_{3}$

[2] 8-oxo-2'-deoxy-guanosine-5'-monophosphate$\mathrm{C}_{10} \mathrm{H}_{14} \mathrm{~N}_{5} \mathrm{O}_{8} \mathrm{P}$

[3] alpha-beta methylene ADP-ribose- $\mathrm{C}_{16} \mathrm{H}_{25} \mathrm{~N}_{5} \mathrm{O}_{13} \mathrm{P}_{2}$

[4] adenosine monophosphate- $\mathrm{C}_{10} \mathrm{H}_{14} \mathrm{~N}_{5} \mathrm{O}_{7} \mathrm{P}$

\begin{tabular}{llll}
\multicolumn{1}{l}{ Table1: Properties of the control compound } & & \\
\hline Title & Formula & Weight & $\begin{array}{c}\text { No. of } \\
\text { Atoms }\end{array}$ \\
\hline $\begin{array}{l}\text { 7-[[5-(3,4-dichlorophenyl)-1,3,4- } \\
\text { oxadiazol- }\end{array}$ & $\mathrm{C}_{20} \mathrm{H}_{20} \mathrm{Cl}_{2} \mathrm{~N}_{8} \mathrm{O}_{3}$ & 491.3306 & 33 \\
$\begin{array}{l}\text { 2-yl]methyl]-1,3-dimethyl-8-piperazin-1- } \\
\text { yl-purine-2,6-dione }\end{array}$ & & & \\
$\begin{array}{l}\text { 8-oxo-2'-deoxy-guanosine-5'- } \\
\text { monophosphate }\end{array}$ & $\mathrm{C}_{10} \mathrm{H}_{14} \mathrm{~N}_{5} \mathrm{O}_{8} \mathrm{P}$ & 363.220621 & 24 \\
$\begin{array}{l}\text { Alpha-beta methylene ADP-ribose } \\
\text { Adenosine monophosphate }\end{array}$ & $\mathrm{C}_{16} \mathrm{H}_{25} \mathrm{~N}_{5} \mathrm{O}_{13} \mathrm{P}_{2}$ & 347.221221 & 23 \\
\hline & $\mathrm{C}_{10} \mathrm{H}_{14} \mathrm{~N}_{5} \mathrm{O}_{7} \mathrm{P}$ & 557.342922 & 36 \\
\hline
\end{tabular}

\section{Docking validation:}

The docking of the ligand 7-[[5-(3, 4-dichlorophenyl)-1,3,4oxadiazol-2-yl]methyl]-1,3-dimethyl-8-piperazin-1-yl-purine-2,6dione with the NUDT5 protein was done as described elsewhere [29] and their interaction featured were calculated using PyMOL [30] to assess docking efficiency.

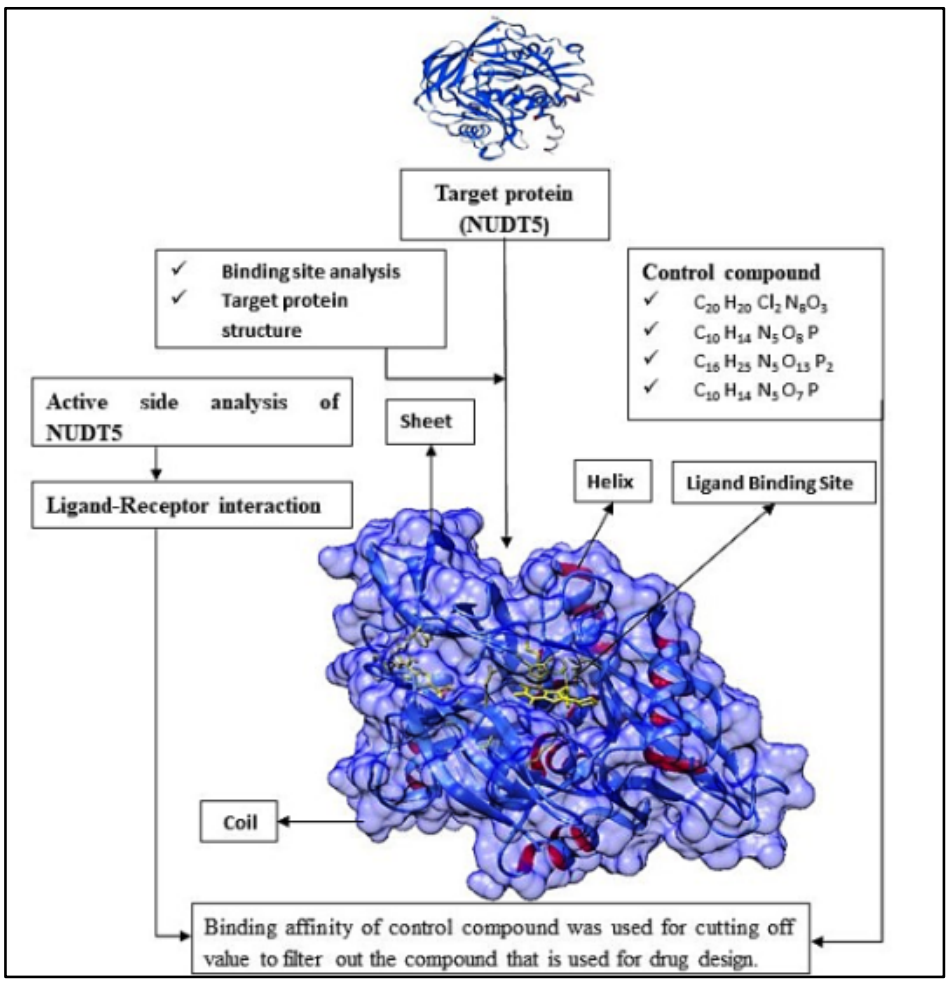

Figure 2: Workflow used in this study

Structure based virtual screening:

The structural-based virtual screening (SBVS) were completed using VSDK (Virtual screening by docking) as described elsewhere 


\section{BIOINFORMATION \\ Discovery at the interface of physical and biological sciences}

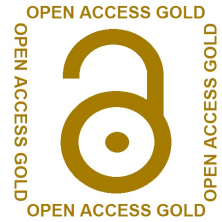

[31-32]. VSDK were chosen mainly because (a) it is freely available (b) easy to operate and (c) it has an ability to take advantage of multiple core processors as well as have much more efficient search of the potential energy surface. Virtual screening was performed using PyRx AutoDock 4.

\section{Receptor-Ligand interaction:}

Ligand-receptor interaction is illustrated using Discovery studio.

Force field used in this study:

The default Force field in the Chimera software is used where required.

\section{Docking:}

Four ligands after applying force field were converted to Auto Dock ligand (pdbqt) and added them to the PyRx for docking with NUDT5 using the Vina Wizard. The interactions were analyzed using Pymol (http://pymol.sourceforge.net/) and Discovery Studio as described in Figure 2.
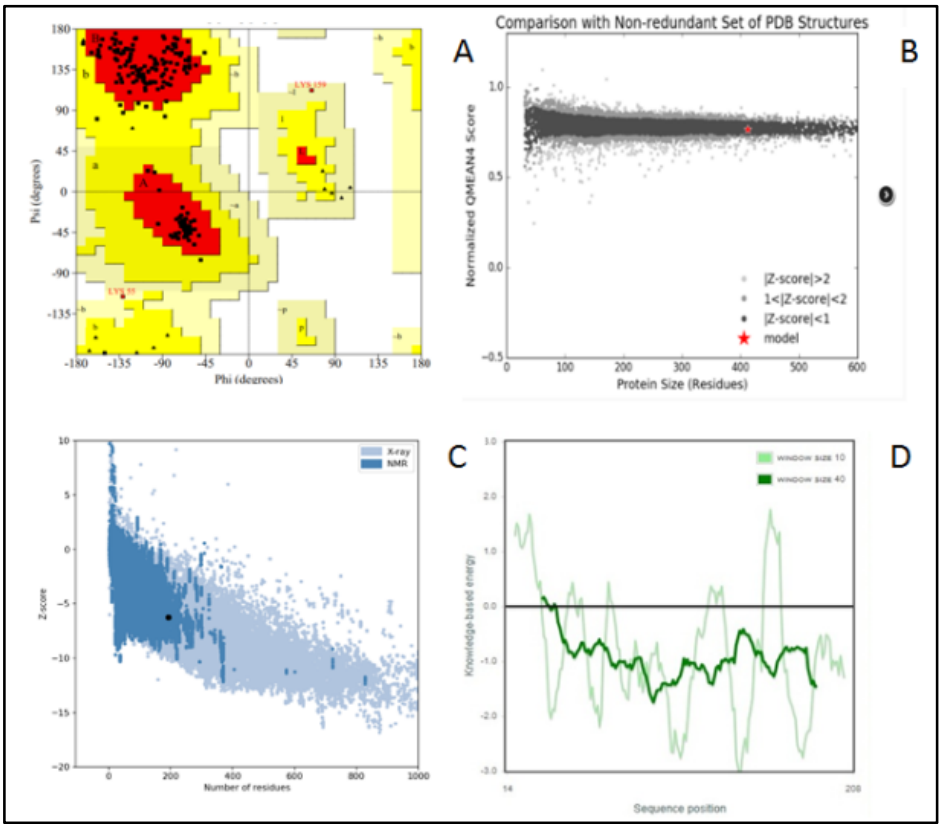

Figure 3: (A) The Ramachandran plot of NUDT5. (B) Q mean based structure validation, which compares the structure to a nonredundant set of PBDs of similar size. The NUDT5 structure, indicated using a red star, lies within the range of scores of similar size structures, indicating its good quality. (C) ProSa Z-score plot of the NUDT5 (D) The local quality of the model is shown in a plot of energy as a function of amino acid sequence position.

Table 2: Ligand with its binding affinity and RMSD values from docking using PyRx

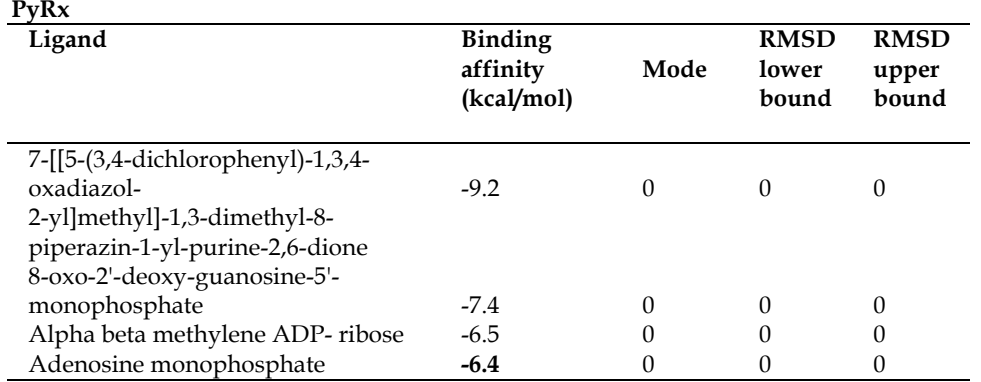

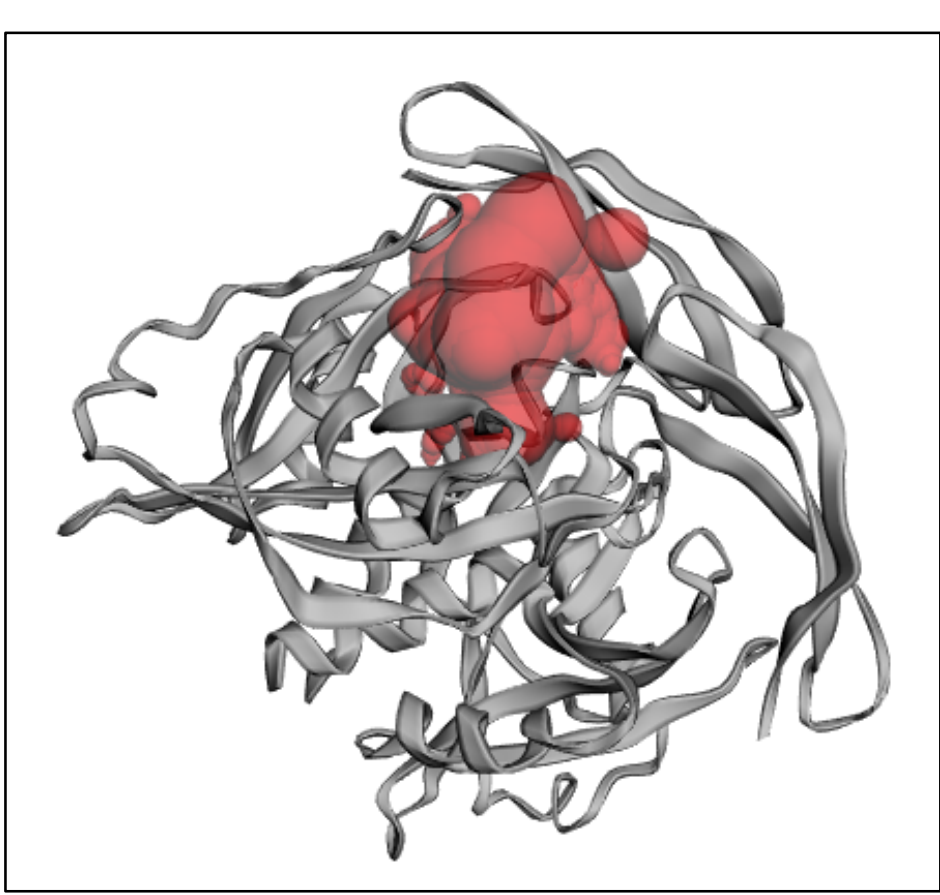

Figure 4: Binding site/active site analysis of NUDT5 using CASTp

\section{Results and Discussion:}

It is of interest to design inhibitors for the breast cancer target NUDT5 using molecular docking based virtual screening followed by molecular docking. A molecular model of NUDT5 was developed using Easy MODELLER using known templates with PDB IDs 5NQR, 3BM4 and 3ACA and validated using standard procedures as shown in Figure 3. Potential binding sites were searched using the CASTp server [28]. The aminoacid residues 


\section{BIOINFORMATION \\ Discovery at the interface of physical and biological sciences}

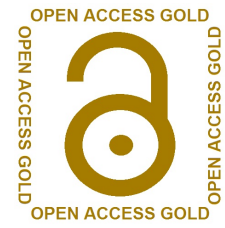

involved in binding pockets are with ligand molecule are thus predicted. Nine possible binding residues such as ILE141, TRP28, ARG51, ALA96, VAL29, GLY97, LEU98, MET132, and CYS139 were found to be involved in interaction with lead inhibitors. Thus, all of these were confirmed as important residues and used to create the grid for docking. The binding pocket has a volume of $392.039^{\circ} \mathrm{A}$ and surface area of 555.407 as calculated by CASTp and shown in Figure 4. The interaction by the analysis of ligand-protein (NUDT5) using Discovery Studio is shown in Figure 5. Features such as hydrophobicity, H-Bond, Ionization, Aromatic compound and charges were calculated.

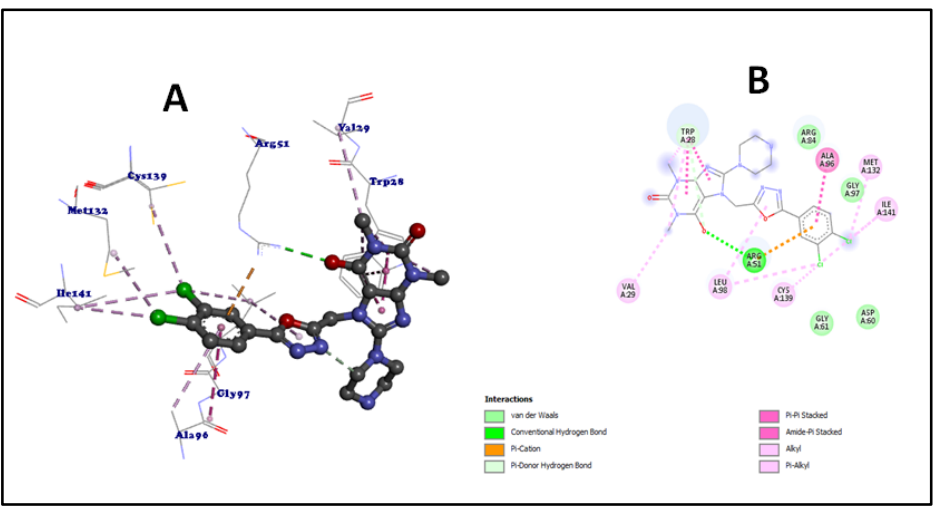

Figure 5: (A) Ligand interaction with the active site of the NUDT5. (B) 2D structure of ligand-receptor interaction

A large number of docking program and search algorithms have been published during last 20 years. It is thus essential to conduct validation before use of these programs. Redocking could serve as validation procedure to determine whether the molecular docking algorithm is able to recover the crystallographic position using computer simulation [29]. In this study, docked ligand pose were compared to the intact ligand pose as measured using PYMOL. The interaction energies and properties were computed for the docked 7-[[5-(3,4-dichlorophenyl)-1,3,4-oxadiazol-2-yl]methyl]-1,3dimethyl-8-piperazin-1-yl-purine-2,6-dione,8-oxo-2'-deoxyguanosine-5'-monophosphate, alpha beta methylene ADP ribose, Adenosine mono-phosphate using PyRxAutodock.

The docking result shows that inhibitor 7-[[5-(3, 4-dichlorophenyl)1, 3, 4-oxadiazol-2-yl] methyl] -1,3-dimethyl-8-piperazin-1-ylpurine-2,6-dione exerted a highest binding free energy of -9.2 $\mathrm{Kcal} / \mathrm{mol}$ and formed a single hydrogen bond with ARG51. All control compounds bind deeply into the binding site and show same overall conformation. Based on the docking result $7-[[5-(3,4-$ dichlorophenyl)-1,3,4-oxadiazol-2-yl]methyl]-1,3-dimethyl-8piperazin-1-yl-purine-2,6-dione were used as positive control. Moreover, the docking studies provide useful insight into the mechanism of reference inhibitor binding to the active site. The Protein-ligand interaction plays a significant role in structure based drug designing. The best confirmation shows that the free energies of binding $(\Delta \mathrm{Gbind} \mathrm{kcal} / \mathrm{mol}$ ) for the four ligands were -9.2 $\mathrm{kcal} / \mathrm{mol},-7.4 \mathrm{kcal} / \mathrm{mol}$ and $-6.5 \mathrm{kcal} / \mathrm{mol}$ and $-6.4 \mathrm{kcal} / \mathrm{mol}$.

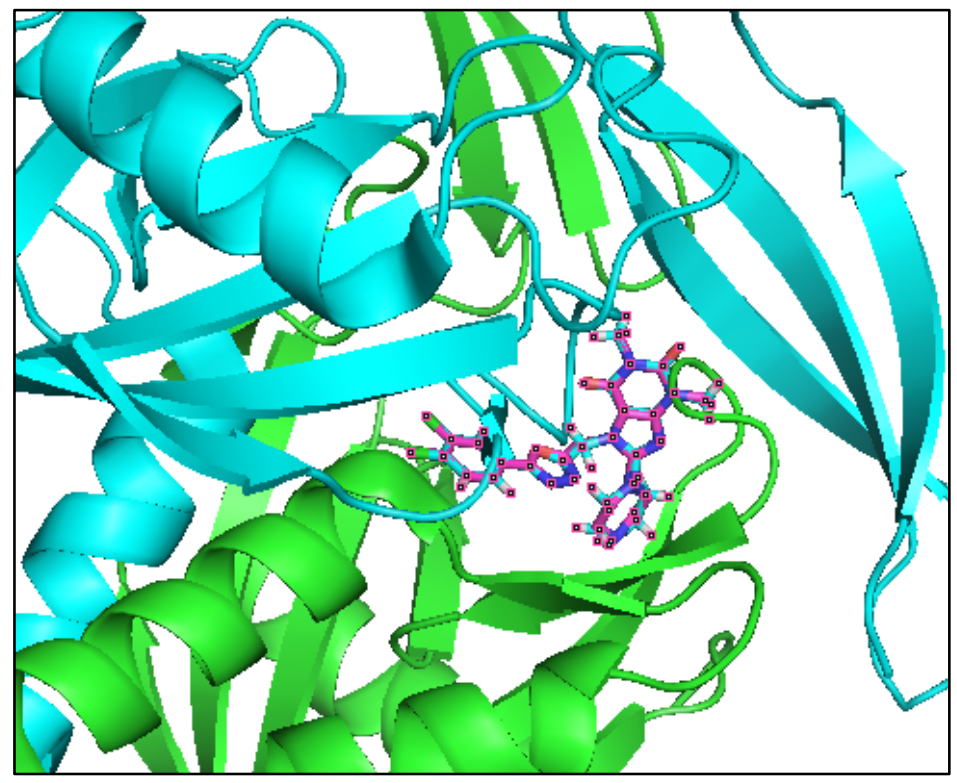

Figure 6: 3D docking interaction analysis of ligand and target using PYMOL

The binding analysis (Table 2) indicates that these molecules can bind to the drug target efficiently and would be potential drugs for NUDT5. The negative and low value of $\Delta$ Gbind indicates strong favorable bonds between protein and the ligand indicating that the ligand was in its most favorable conformations. The molecular docking was applied to explore the binding mechanism and studies on the novel ligand against the NUDT5 protein showed that the free binding energy for the inhibitor was small, indicating that the ligand binds favorably to the binding site. The ligand was observed as the best inhibitor candidate, which may be considered as a potential ligand for treatment of Breast cancer. The differences of binding affinities might be mainly attributed to the different hydrogen bond interactions and the orientation of ligands in the binding pocket. Therefore, this study thus helps to focus on in silico drug design for breast cancer based on its essential protein, NUDT5 


\section{BIOINFORMATION \\ Discovery at the interface of physical and biological sciences}

identified as potential drug target. We show that the docked ligand binds at the same active site of the protein where the natural inhibitor (PDB ID: 5NWH) was bound (Figure 6) for further consideration and validation.

\section{Conclusion:}

Design and development of potential inhibitors to NUDT5 is of interest in the treatment of breast cancer. Hence, we report the structure based binding features of a lead compound 7-[[5-(3,4dichlorophenyl)-1,3,4-oxadiazol-2-yl]methyl]-1,3-dimethyl-8piperazin-1-yl-purine-2,6-dione with NUDT5 for further in vitro and in vivo validation.

\section{Conflict of interest:}

The authors declare no conflicts of interest.

\section{Acknowledgements:}

We would like to thank the Department of Biotechnology and Genetic Engineering, Noakhali Science and Technology University, Noakhali 3814, Bangladesh for supporting this research.

\section{References:}

[1] Page BDG et al. Nat Commun. 2019 10:5050. [PMID: 29343827]

[2] de la Mare JA et al. Recent Pat Anticancer Drug Discov. 2014 9:153. [PMID: 24171821]

[3] Veronesi U et al. Lancet. 2005 365:1727. [PMID: 15894099]

[4] Merino Bonilla JA et al. Radiologia. 2017 59:368. [PMID: 28712528]

[5] Anastasiadi Z et al. Updates Surg. 2017 69:313. [PMID: 28260181]

[6] Bray F et al. CA Cancer J Clin. 2018 68: 394.[ PMID: 30207593]

[7] Pickup KE et al. Cancers (Basel). 2019 10:11. [PMID: 31510016]

[8] Arimori T et al. Nucleic Acids Res. 2011 39:8972. [PMID: 21768126]

[9] Zhang LQ et al. Mol Cell Biochem. 2012 36:377. [PMID: 22200976]

[10] Bessman MJ et al. J Biol Chem. 1996 271:25059. [PMID: 8810257]
[11] Zha M et al. J Mol Biol. 2006 364:1021. [PMID: 17052728]

[12] Yu HN et al .Biochem Biophys Res Commun. 2007 354:764. [PMID: 17261271]

[13] McLennan AG et al. Cell Mol Life Sci 2005 63:123.

[14] Mildvan AS et al. Arch Biochem Biophys. 2005 433:129. [PMID: 15581572]

[15] Ito R et al. J Biochem. 2011 149:731. [PMID: 21389046]

[16] Arimori T et al. Nucleic Acids Res. 2011 39:8972. [PMID: 21768126]

[17] Yang H et al. J Biol Chem. 2000 275:8844. [PMID: 10722730]

[18] Arimori T et al. Fukuoka Igaku Zasshi. 2011 102:303. [PMID: 22351996]

[19] Gasmi L et al. Biochem J. 1999 344:331. [PMID: 10567213]

[20] Hassa PO et al. Microbiol Mol Biol Rev. 2006 70:789. [PMID: 16959969]

[21] Gibson BA et al. Nat Rev Mol Cell Biol. 2012 13:411. [PMID: 22713970]

[22] Formentini L et al. J Biol Chem. 2009 284:17668.[PMID: 19411252]

[23] Perraud AL et al. J Biol Chem. 2003 278:1794. [PMID: 12427752]

[24] Zha M et al. J Mol Biol. 2008 379:568. [PMID: 18462755]

[25] Bourne PE et al. Nucleic Acids Res. 2004 32:D223. [PMID: 14681399]

[26] Hori M et al. Free Radic Biol Med. 2010 48:1197. [PMID: 20144704]

[27] Richardson JS et al. Advances in Protein Chemistry 1981 34: 167339. [PMID: 7020376]

[28] Dundas J et al. Nucleic Acids Res. 2006 34:W116. [PMID: 16844972]

[29] Kamiya H et al. DNA Repair (Amst). 2009 8:1250. [PMID: 19699693]

[30] Osipovitch M et al. J Struct Funct Genomics. 2015 16:101. [PMID: 26573864]

[31] Shen J et al. Curr Med Chem. 2003 10:2327. [PMID: 14529345]

[32] Kroemer RT et al. Curr Protein Pept Sci. 2007 8:312. [PMID: 17696866]

Edited by P Kangueane Citation: Sultana et al. Bioinformation 15(11): 784-789 (2019) License statement: This is an Open Access article which permits unrestricted use, distribution, and reproduction in any medium, provided the original work is properly credited. This is distributed under the terms of the Creative Commons Attribution License 


\section{BIOINFORMATION}

Discovery at the interface of physical and biological sciences
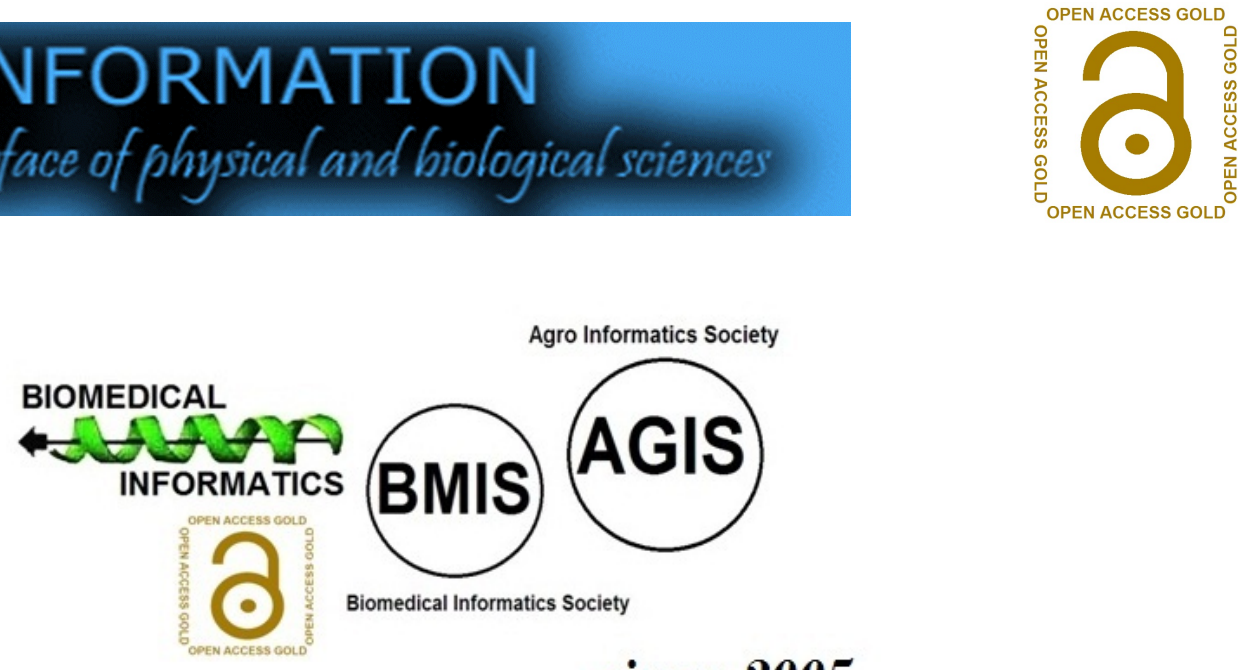

since 2005

\section{BIOINFORMATION}

Discovery at the interface of physical and biological sciences

\section{indexed in}

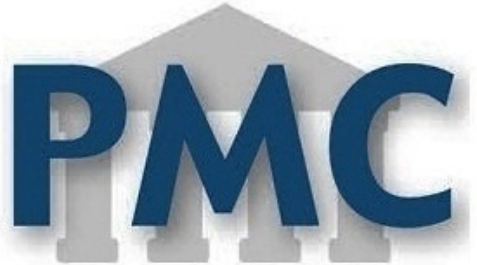

PublMed

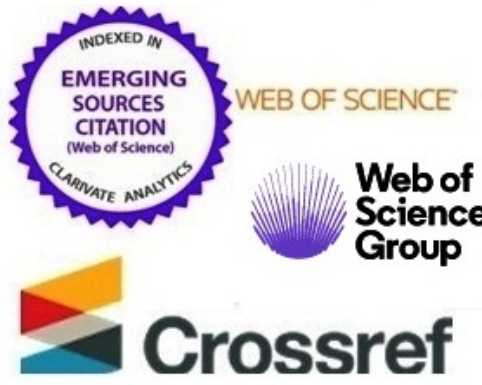

EBSCO

Web of

Science

roup

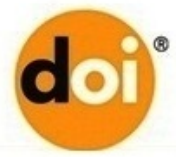

ResearchGate
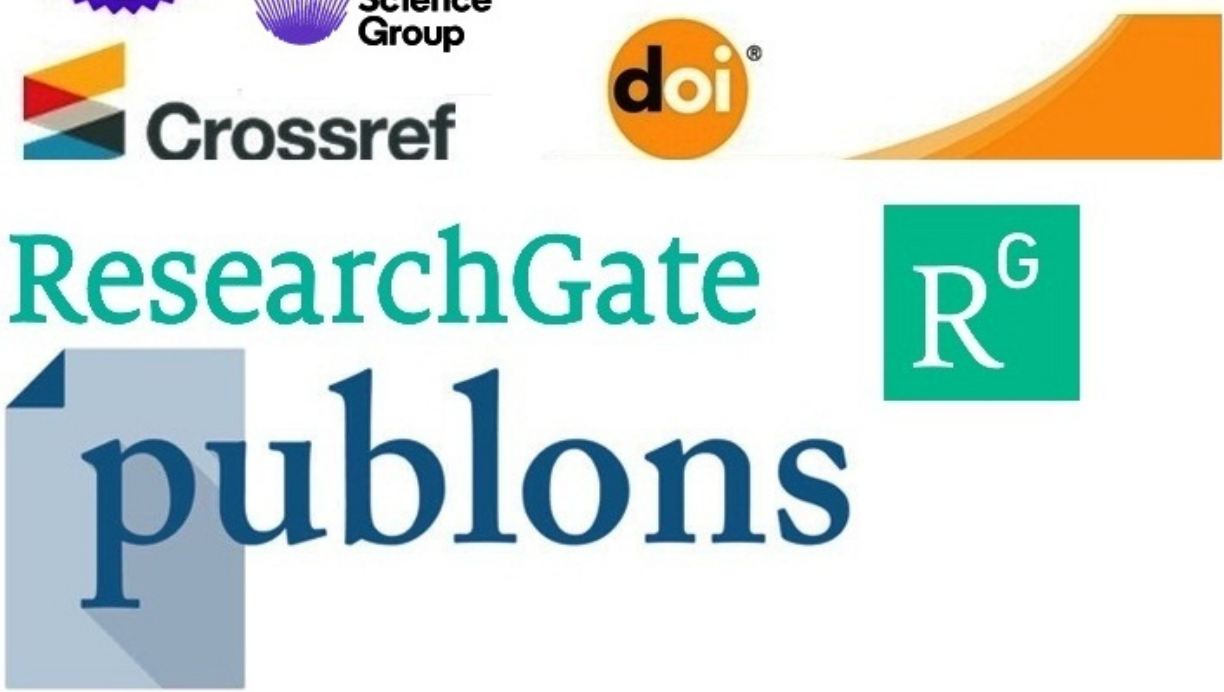